\title{
Microstructural Insights into Pb-Caustic Stress Corrosion Cracking in Alloy 690TT
}

\author{
G.B. Mazzei ${ }^{1}$, A. D. Horner ${ }^{2}$, F. Scenini ${ }^{1}$ and M.G. Burke ${ }^{3}$
}

${ }^{1}$ University of Manchester, United States, ${ }^{2}$ Rolls-Royce plc, United States, ${ }^{3}$ University of Manchester, Manchester, United Kingdom

$\mathrm{Pb}$-caustic Stress Corrosion Cracking (PbSCC) can occur in the secondary side of pressurized water reactors, affecting the integrity of the Alloy 690 (Ni-30Cr-10Fe) steam generator tubes [1]. PbSCC can occur in concentrated caustic conditions that might arise in crevices where $\mathrm{Pb}$ (a contaminant) may accumulate. A hybrid mechanism consisting of a film-rupture/slip-dissolution mechanism aided by the occurrence of dealloying has been proposed to explain PbSCC of Ni-base alloys, but definitive data are required for confirmation. The present work aims to improve the mechanistic understanding of the early stages of cracking through the use of advanced electron microscopy techniques with particular attention on surface finish effects on PbSCC initiation.

PbSCC tests were performed on C-rings samples of thermally-treated Alloy 690 (A690TT) compressed (1.5\% strain at the apex), and exposed in a $\mathrm{NaOH}$ solution containing $1000 \mathrm{ppm}$ of $\mathrm{PbO}$ at $310^{\circ} \mathrm{C}\left(\mathrm{pH}_{310^{\circ} \mathrm{C}} 10\right)$ for $500 \mathrm{~h}$. Surface conditions examined were as-received (AR) from tube processing, or polished to remove the deformed near-surface layer. Post-test characterisation included SEM (Zeiss Sigma FEG-SEM equipped with Oxford Instruments X-Max 150 SDD, an EBSD detector and Aztec analysis system), analytical S/TEM (FEI Tecnai T20 LaB 6 S/TEM operated at $200 \mathrm{kV}$, and an FEI Talos G2 S/TEM with X-FEG and Super X), and cross-section TEM specimen preparation using an FEI Helios 660 FIB/FEGSEM.

Evaluation of metallographic cross-sections prepared from the tested C-ring samples revealed that the transgranular crack depth was not affected by surface condition $(\sim 120 \mu \mathrm{m})$, although the polished specimen contained $\sim 4$ times more cracks than the sample with the AR surface finish [2]. In addition, analysis of the post-test samples revealed that the PbSCC environment had different effects on AR and polished surface. The cross-sectioned AR specimen exhibited a near-surface deformed zone characterized by an outer ultrafinegrained layer and a deformed layer beneath it. After the PbSCC test, this deformed surface layer had oxidized, resulting in an $\mathrm{Cr}$-Fe-enriched oxide containing $\mathrm{Pb}$. In addition, "islands" of Ni metal were observed within the oxidized layer, Fig. 1. In contrast, localised attack in the form of corrosion slots containing $\mathrm{Cr}_{2} \mathrm{O}_{3}$ (Fig. 2) was observed on the surface of the polished specimen. Electron diffraction and EBSD confirmed that that these crystallographic slots formed along $\{110\}$ planes and some $\{100\}$ planes.

The analysis of FIB cross-section TEM specimens and crack-tip samples further confirmed the presence of metallic Ni as islands (Fig. 1 (c)-(e)) and along the flanks of cracks originated from corrosion slots (Fig. 2 (f)) with more fracture surface cross-section analysis in [2]), indicating that de-alloying occurred under the $\mathrm{Pb}$ caustic conditions. The presence metallic Ni surrounded by oxide can be explained by the oxidation behaviour of $\mathrm{Ni}, \mathrm{Cr}$ and $\mathrm{Fe}$ in this environment: $\mathrm{Ni}$ is more noble then $\mathrm{Cr}$ and $\mathrm{Fe}$. Thus, metallic Ni would be "left behind" during the oxidation of the deformed zone in the AR specimen.

Tunnel corrosion along $\{110\}$ planes has been reported by Scamans and Swann [3]; they proposed that preferential oxidation along specific crystallographic planes at crack tips was related to SCC initiation [3-4]. In particular, these observations support the hypothesis that anodic dissolution is a major factor, supporting a film-rupture/slip-dissolution mechanism to the case of PbSCC in A690TT [4]. Based on these observations, the near-surface deformed layer promoted the oxidation limiting any crystallographic crack nucleation within this region, unlike the crystallographic slot formation observed for the polished specimens, which led to the higher proportion of cracks [2]. These results are consistent with a film-rupture/slip-dissolution mechanism, assisted by de-alloying for Pb-caustic SCC of A690TT. 
The authors wish to acknowledge support from the Engineering and Physical Sciences Research Council (grant EP/L01680X/1), Rolls Royce plc and the Centre for Doctoral Training in Materials for Demanding Environment (CDT M4DE). This work was supported by the Henry Royce Institute for Advanced Materials, funded through EPSRC grants EP/R00661X/1 and EP/P025021/1.

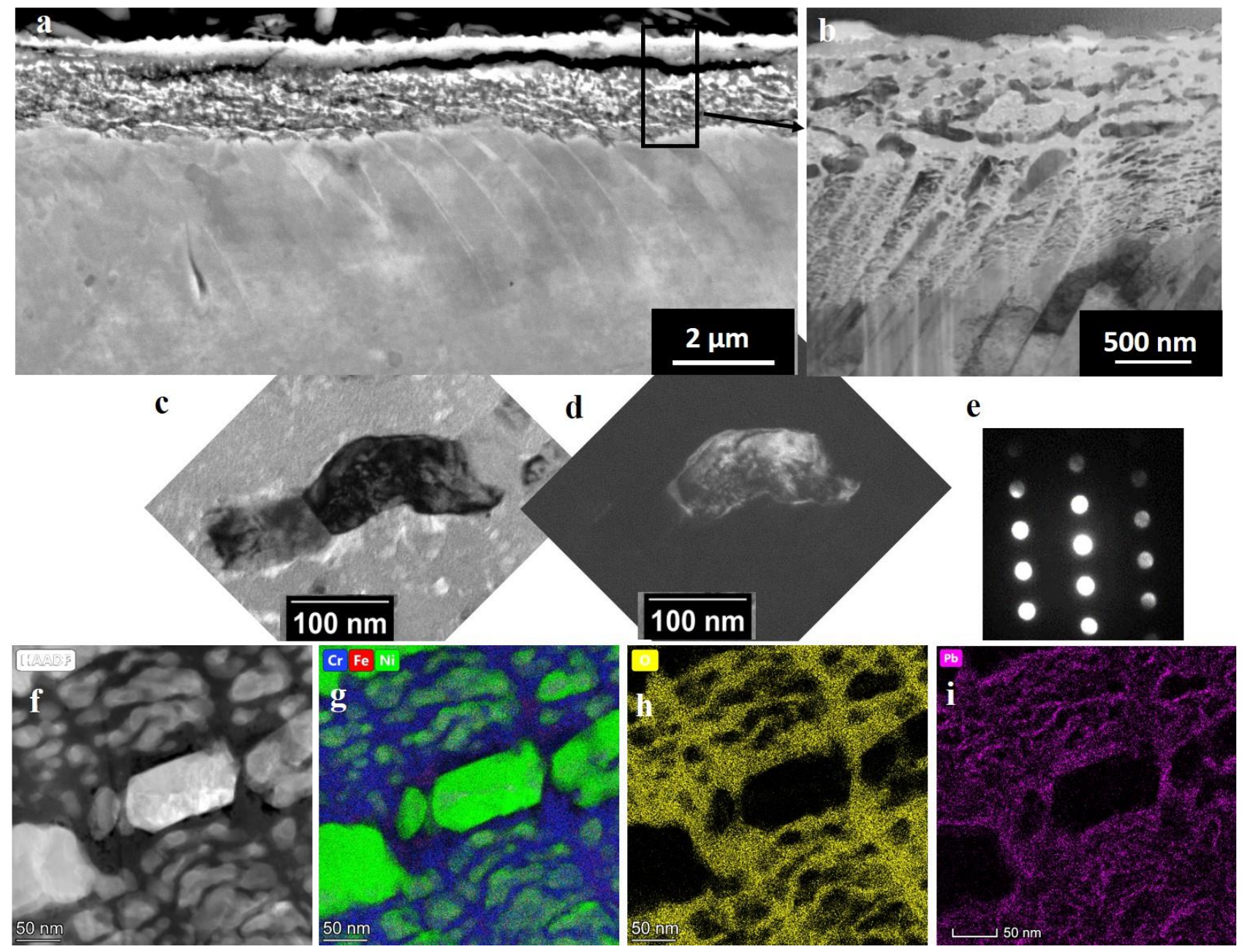

Figure 1. (a) SE image of cross-sectioned post-test AR sample. (b) HAADF STEM image from the oxidised region; (c) BF and (d) corresponding DF TEM images of a nodule of metallic Ni, with (e) associated [013] CBED pattern. (f) HAADF STEM image, and corresponding STEM-EDX maps for (g) Ni K $\alpha$ (green) - $\mathrm{Cr} \mathrm{K} \alpha$ (blue) - $\mathrm{Fe} \mathrm{K} \alpha$ (red), (h) $\mathrm{O} \mathrm{K} \alpha$ and (i) $\mathrm{Pb} \mathrm{M} \alpha$ showing Ni metal regions within the oxidised layer. 


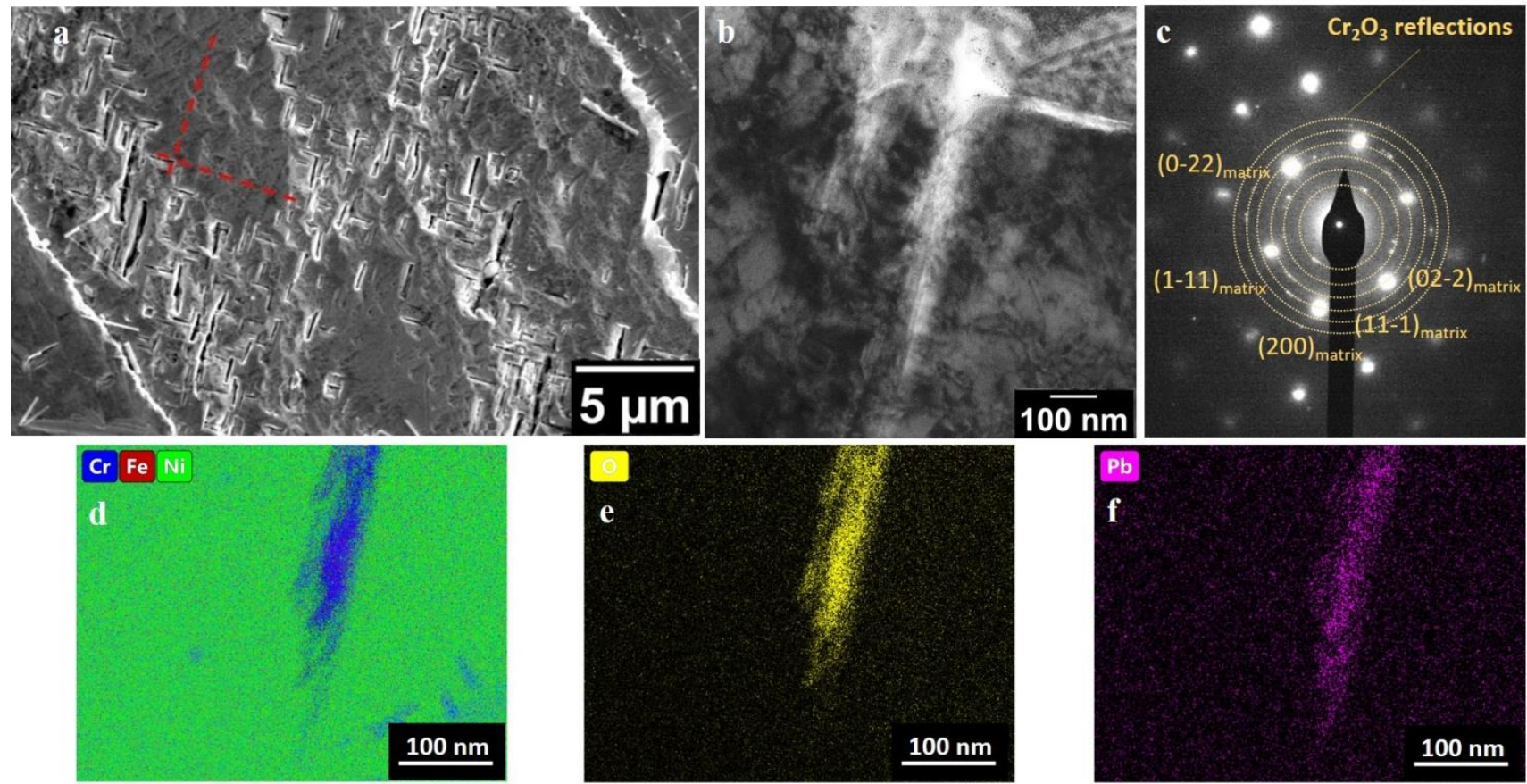

Figure 2. (a) SE image of post-PbSCC tested polished surface containing crystallographic slots (red lines); (b) TEM image of a corrosion slot; (c) [110] SADP with Cr2O3 in slot; STEM-EDX maps of (d) Ni Ka (green), $\mathrm{Cr} \mathrm{K} \alpha$ (blue), and $\mathrm{Fe} \mathrm{K} \alpha$ (red), (e) $\mathrm{O} \mathrm{K} \alpha$ and (f) $\mathrm{Pb} \mathrm{M} \alpha$.

\section{References}

[1] R.W. Staehle, in $12^{\text {th }}$ Inv. Conf. Environ. Degradation of Materials Nuclear Power Systems (TMS, 2005) $1163-1210$.

[2] G.B. Mazzei, Lead-Induced Stress Corrosion Cracking of Alloy 690TT in Caustic Environments, University of Manchester (UK), 2021.

[3] G.M. Scamans, P.R. Swann, Corros. Sci. 18 (1978) 983-995.

[4] M.G. Burke, et al., in $13^{\text {th }}$ Int. Conf. Environ. Degradation of Materials Nuclear Power Systems (TMS, 2007), $1-16$ 